\title{
Hidatidose hepática calcificada
}

\author{
Calcified hepatic hydatid cysts
}

Descreve-se 0 caso de uma mulher de 73 anos, com patologia osteoarticular degenerativa. Foi trazida ao serviço de urgência por dispneia súbita, associada a palpitações. Realizou angiografia das artérias pulmonares, por tomografia computorizada, para exclusão de tromboembolismo pulmonar tendo sido detectados, incidentalmente, 2 volumosos quistos hidáticos calcificados (Fig 1 e 2). Optou-se por manter vigilância dos quistos.

Apresentam-se as imagens pela exuberância da hidatidose hepática calcificada.

Os quistos hidáticos são o resultado da infeção pela forma de larva do Echinococcus granulosus. 0 hospedeiro definito do E. granulosus é o cão, e os hospedeiros intermediários a ovelha e 0 porco. 0 homem também é um hospedeiro intermediário, sendo a infeção geralmente adquirida por via fecal-oral. ${ }^{1}$

Epidemiologicamente, a região sul de Portugal é altamente endémica, estando $0 \mathrm{E}$. granulosus também presente no restante território. ${ }^{2} \mathrm{~A}$ incidência pode ser de 50 por 100. 000 pessoas/ano e a prevalência pode atingir $5-10 \%$ em zonas endémicas. ${ }^{1}$

Os quistos hidáticos podem-se formar em qualquer local do corpo, embora o mais frequente seja o fígado (68. 8-75\%), seguido do pulmão (17. 2-22\%). (3) A infeção é assintomática por longos períodos e os sintomas são o resultado do crescimento ou rutura dos quistos. ${ }^{4}$

A resposta imunitária do hospedeiro ao quisto origina uma cápsula fibrótica ao redor do mesmo, que posteriormente calcifica. ${ }^{4}$ Quando 0 quisto está totalmente calcificado, o parasita está inactivo ou morto. ${ }^{1}$

0 diagnóstico centra-se em exames de imagem, preferencialmente a ecografia. Os testes serológicos podem complementar os exames de imagem e ajudar no seguimento pós-operatório. Atualmente, muitos dos testes serológicos que foram desenvolvidos são utilizados apenas para fins de investigação e não são amplamente aplicáveis em contexto clínico, especialmente nos países em desenvolvimento. Assim, é dada uma grande importância às modalidades de imagem no diagnóstico. ${ }^{1}$ Na nossa doente, dado que os testes serológicos não fazem o diagnóstico e dado que o nosso Hospital não dispõe desses mesmos testes, optou-se pela não realização dos mesmos.

0 tratamento depende do estadio, localização, número e dimensão do quisto. Nalguns casos é aconselhada vigilância ecográfica, noutros podem ser utilizados os anti-helmínticos, como o Albendazole ou o Mebendazole, e noutros ainda, é recomendada a cirurgia ou tratamentos percutâneos.

Figura 1. Corte axial de tomografia computorizada de tórax, ao nível do andar superior do abdómen, onde é visível um exuberante quisto hidático hepático calcificado, com quisto satélite mais pequeño

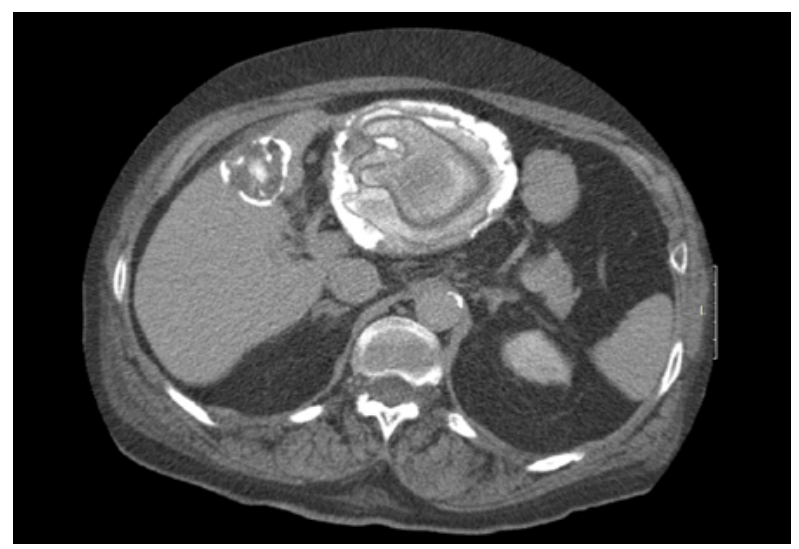

Figura 2. Outra perspetiva do quisto hidático hepático calcificado num corte sagital de tomografia computorizada de tórax.

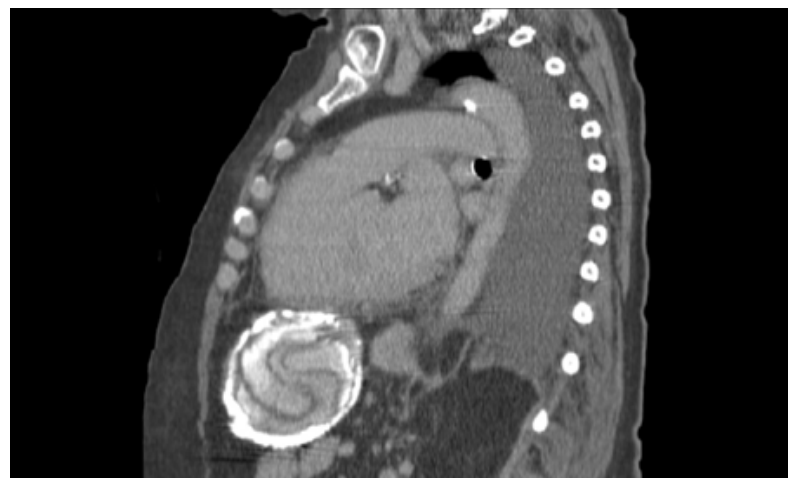

\section{Bibliografia}

1. Pakala T, Molina M, Wu GY. Hepatic Echinococcal Cysts: A Review. J Clin Trans Hepatol. 2016; 4: 39-46.

2. Nunnari G, Pinzone MR, Gruttadauria S, Celesia BM, Madeddu G, Malaguarnera G et al. Hepatic echinococcosis: Clinical and therapeutic aspects. World J Gastroenterol. 2012; 18: 1448-1458

3. Savioli L, Daumerie D, WHO Department of Control of Neglected Tropical Diseases. Sustaining the drive to overcome the global impact of neglected tropical diseases: second WHO report on neglected tropical diseases [e-book]. World Health Organization; 2013 [consultado em 2016 Jul 04]. Disponivel em: http://www.who.int/ neglected_diseases/9789241564540/en/

4. Srinivas MR, Deepashri B, Lakshmeesha MT. Imaging Spectrum of Hydatid Disease: Usual and Unusual Locations. Pol J Radiol. 2016; 81: 190-205

\section{Diagnóstico: Hidatidose hepática calcificada}

Joana Carlos-Alves ${ }^{1}$, Luís Santos ${ }^{2}$,

Raquel Lopéz, Diana Guerra ${ }^{3}$

'Serviço de Medicina Interna.

${ }^{2}$ ULSAM - Hospital de Santa Luzia.

3Viana do Castelo (Portugal)

Correspondencia: joanamiriam.carlos@gmail.com

Como citar este artículo: Carlos-Alves JC, Santos L, Lopéz R, Guerra D

Hidatidose hepática calcificada. Galicia Clin 2017; 78 (3): 145

Recibido: 03/11/2016; Aceptado: 20/12/2016 